\title{
Charge Abundances of the Solar Wind lons Inferred from Cometary X-Ray Spectra
}

\section{Citation}

Kharchenko, V., Matt Rigazio, A. Dalgarno, and V. A. Krasnopolsky. 2003. "Charge Abundances of the Solar Wind lons Inferred from Cometary X-Ray Spectra." The Astrophysical Journal 585 (1): L73-75. https://doi.org/10.1086/374209.

\section{Permanent link}

http://nrs.harvard.edu/urn-3:HUL.InstRepos:41397462

\section{Terms of Use}

This article was downloaded from Harvard University's DASH repository, and is made available under the terms and conditions applicable to Other Posted Material, as set forth at http:// nrs.harvard.edu/urn-3:HUL.InstRepos:dash.current.terms-of-use\#LAA

\section{Share Your Story}

The Harvard community has made this article openly available.

Please share how this access benefits you. Submit a story.

Accessibility 
The Astrophysical Journal, 585:L73-L75, 2003 March 1

(C) 2003. The American Astronomical Society. All rights reserved. Printed in U.S.A.

\title{
CHARGE ABUNDANCES OF THE SOLAR WIND IONS INFERRED FROM COMETARY X-RAY SPECTRA
}

\author{
V. Kharchenko, Matt Rigazio, and A. Dalgarno \\ Harvard-Smithsonian Center for Astrophysics, 60 Garden Street, Cambridge, MA 02138; vkharchenko@cfa.harvard.edu \\ AND \\ V. A. KRASNOPOLSKY \\ Department of Physics, Catholic University of America, 620 Michigan Avenue, NE, Washington, DC 20064 \\ Received 2002 December 11; accepted 2003 January 21; published 2003 February 3
}

\begin{abstract}
An emission spectrum of X-rays from comet McNaught-Hartley (C/1999 T1) detected with the Chandra Xray telescope is analyzed on the assumption that it results from electron captures by heavy ions of the solar wind colliding with the atoms and molecules of the cometary atmosphere. An accurate value of the relative abundance of $\mathrm{O}^{+8}$ and $\mathrm{O}^{+7}$ ions is obtained by comparing the spectrum derived from the measurement data with the predicted spectrum. A close match is found for an abundance ratio of $\mathrm{O}^{+8}$ to $\mathrm{O}^{+7}$ of $0.34 \pm 0.07$, the uncertainty reflecting the measurement statistics. A similar analysis of the contribution from captures by $\mathrm{Ne}^{+9}$ ions leads to an abundance ratio of $\mathrm{Ne}^{+9}$ to $\mathrm{O}^{+7}$ of 0.02 with an uncertainty of $40 \%$. The spectrum consists of many unresolved lines. The brightest feature is composed mostly of the $2{ }^{3} S_{1} \rightarrow 1{ }^{1} S_{0}$ spin-forbidden line of $\mathrm{O}^{+6}$ at $561 \mathrm{eV}$ with $74 \%$ of the intensity and the $2{ }^{3} P_{1} \rightarrow 1{ }^{1} S_{0}$ intercombination line at $568 \mathrm{eV}$ with $12 \%$. The strongest of the $\mathrm{O}^{+7}$ lines is the $\mathrm{Ly} \alpha$ transition at $654 \mathrm{eV}$ with an intensity of $29 \%$, relative to the $\mathrm{O}^{+6}$ lines. The sensitivity of cometary X-ray spectra to variations in the abundances of highly charged oxygen ions in the solar wind is investigated.
\end{abstract}

Subject headings: atomic processes — comets: general - X-rays: general

Comets are observed to be sources of soft X-rays and extreme-ultraviolet radiation (Lisse et al. 1996, 1999a, 1999b, 2001; Krasnopolsky et al. 1997, 2002; Dennerl, Englhauser, \& Trümper 1997; Mumma, Krasnopolsky, \& Abbott 1997; Owens et al. 1998; Krasnopolsky, Mumma, \& Abbott 2000; Krasnopolsky \& Mumma 2001). The presence of features in the spectrum (Krasnopolsky \& Mumma 2001; Lisse et al. 2001; Cravens 2002; Krasnopolsky et al. 2002) supports the suggestion of Cravens (1997) that the emission arises from excited states of multicharged ions of the solar wind populated by charge transfer in collisions with the neutral particles of the cometary atmospheres. The spectral resolution of the first observations was sufficient to distinguish between the slow and fast components of the solar wind (Schwadron \& Cravens 2000; Kharchenko \& Dalgarno 2001) but not to establish definitively the identity and relative abundances of the solar wind ions. With improved resolution, the features could be attributed to emission lines of multiply charged ions of oxygen, neon, carbon, silicon, and magnesium (Krasnopolsky et al. 2002). Given an accurate model of the capture probabilities in collisions of ions with $\mathrm{H}_{2} \mathrm{O}$, the major constituent of the coma, and of the subsequent radiative cascade, a quantitative measure of the composition of the solar wind can be obtained.

The main features in the spectrum of comet McNaughtHartley at energies between $500 \mathrm{eV}$ and $1 \mathrm{keV}$ (Krasnopolsky et al. 2002) are lines of $\mathrm{O}^{+6}$ and $\mathrm{O}^{+7}$ terminating in the ground states. The capture probabilities may be determined by a theoretical analysis of the laboratory data on the spectrum resulting from $\mathrm{O}^{+8}$ ions traversing a gas of $\mathrm{H}_{2} \mathrm{O}$ as was done for $\mathrm{Ne}^{+10}$ (Rigazio, Kharchenko, \& Dalgarno 2002) for collisions in gases of $\mathrm{He}, \mathrm{Ne}, \mathrm{H}_{2}, \mathrm{CO}_{2}$, and $\mathrm{H}_{2} \mathrm{O}$ (Greenwood et al. 2000; Beiersdorfer et al. 2001). Taken in conjunction with the known transition probabilities of the hydrogen-like $\mathrm{O}^{+7}$, an accurate prediction of the charge transfer spectrum can be made. For the helium-like $\mathrm{O}^{+6}$ ions, the procedure is more complicated because capture occurs into singlet and triplet states. The transition probabilities for allowed lines and forbidden intercom- bination lines have been calculated for $\mathrm{O}^{+6}$ and other helium-like ions by Johnson et al. (2002). For $\mathrm{O}^{+6}$, the triplet states decay radiatively into lower triplet states, eventually arriving in the $2{ }^{3} S_{1}$ state, with the exception of the triplet $2{ }^{3} P_{1}$ state, which radiates preferentially in an electric dipole transition at $568 \mathrm{eV}$ to the ground $1{ }^{1} S_{0}$ state (Drake \& Dalgarno 1969). The triplet $2{ }^{3} S_{1}$ state decays to the $1{ }^{1} S_{0}$ state by a relativistic magnetic dipole transition at $561 \mathrm{eV}$. The population ratios may be obtained from an analysis of the laboratory data on the soft X-ray emission spectrum produced by $\mathrm{O}^{+7}$ ions in $\mathrm{H}_{2} \mathrm{O}$ gas (Greenwood et al. 2000, 2001), recognizing that the strong $2{ }^{3} S_{1}-1{ }^{1} S_{0}$ line of $\mathrm{O}^{+6}$ at $561 \mathrm{eV}$ is absent from the spectrum measured in ion beam experiments (Kharchenko \& Dalgarno 2001) because of the long radiative lifetime, $1.0 \mathrm{~ms}$, of the $2{ }^{3} S_{1}$ state (Drake 1971).

The predicted intensities of the $\mathrm{O}^{+6}$ and $\mathrm{O}^{+7}$ lines appearing at energies above $500 \mathrm{eV}$ relative to, respectively, the $2{ }^{3} S_{1}$ $1{ }^{1} S_{0}$ line and the $2{ }^{2} P-1{ }^{2} S$ line are presented in Tables 1 and 2. The Ly $\alpha$ line at $653 \mathrm{eV}$ is the strongest line of the $\mathrm{O}^{+7}$ spectrum. The $2{ }^{3} S_{1}-1{ }^{1} S_{0}$ line at $561 \mathrm{eV}$ is the strongest line of the $\mathrm{O}^{+6}$ spectrum. The lines of the singlet spectrum are less intense, the strongest being the $2{ }^{1} P_{1}-1{ }^{1} S_{0}$ line at $574 \mathrm{eV}$. The relative intensities of the lines at 561,568 , and $574 \mathrm{eV}$ are $1.00: 0.16: 0.09$.

Nine features have been observed by the Chandra telescope in the X-ray emission spectrum of comet McNaught-Hartley (Krasnopolsky et al. 2002). Five features lie above $500 \mathrm{eV}$ at $560 \pm 3,650 \pm 6,780 \pm 23,845 \pm 19$, and $945 \pm 34 \mathrm{eV}$. Their intensities measured in units of $10^{23}$ photons per second are, respectively, $26.1 \pm 2.3,9.0 \pm 1.1,1.3 \pm 0.5,1.4 \pm 0.5$, and $0.7 \pm 0.35$ (Krasnopolsky et al. 2002). The features at 560, 650,780 , and $845 \mathrm{eV}$ can be attributed to groups of lines of $\mathrm{O}^{+6}$ and $\mathrm{O}^{+7}$. The feature at $945 \pm 34 \mathrm{eV}$ may be due to transitions of $\mathrm{Ne}^{+8}$, the strongest of which occur at 905, 912, and $922 \mathrm{eV}$. We can reproduce the observed cometary spectra by adopting solar wind ion abundance ratios $\left[\mathrm{O}^{+8}\right] /\left[\mathrm{O}^{+7}\right]=0.34$ and $\left[\mathrm{Ne}^{+9}\right] /\left[\mathrm{O}^{+7}\right]=0.02$. The corresponding radiative intensi- 


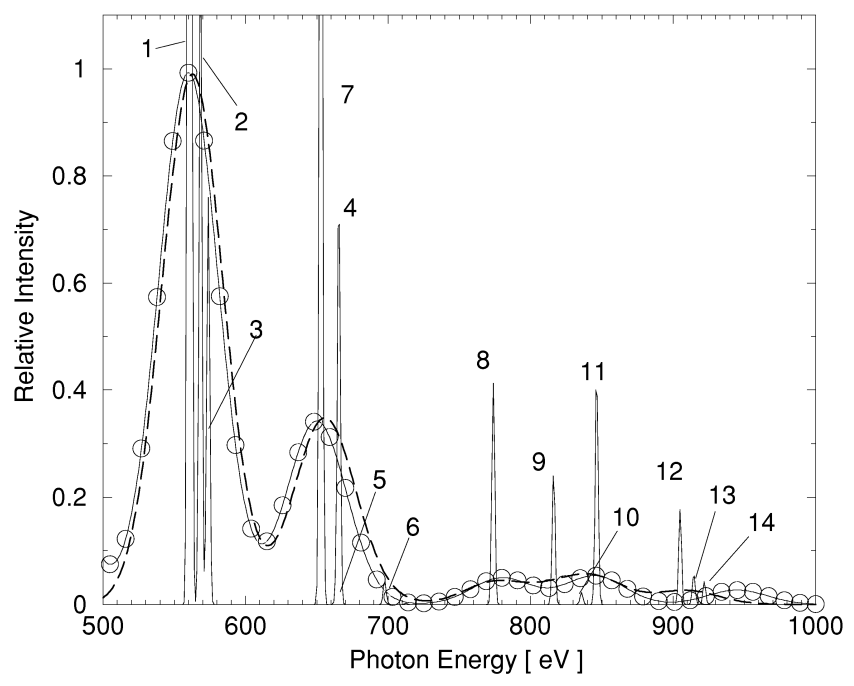

FIG. 1.-X-ray emission spectra of comet McNaught-Hartley detected by the Chandra X-ray telescope. The solid curve with circles is the best-fit curve of the spectrum of Krasnopolsky et al. (2002), and the dashed curve is our theoretical calculation of the cometary emission spectrum induced by the charge transfer mechanism. The numbers refer to the emission lines of the individual ions listed in Tables 1 and 2. The $\mathrm{Ne}^{+8}$ emission lines are (12) $2{ }^{3} S \rightarrow 1{ }^{1} S$ at $905 \mathrm{eV}$, (13) $2{ }^{3} P \rightarrow 1{ }^{1} S$ at $914 \mathrm{eV}$, and (14) $2{ }^{1} P \rightarrow 1{ }^{1} S$ at $922 \mathrm{eV}$. The relative intensities of emission lines are calculated for relative abundances of the solar wind ions $\left[\mathrm{O}^{+7}\right]:\left[\mathrm{O}^{+8}\right]:\left[\mathrm{Ne}^{+9}\right]=1: 0.34: 0.02$. The photon energy resolution has been taken to be $45 \mathrm{eV}$. The theoretical spectrum with an energy resolution of $1 \mathrm{eV}$ is indicated by the solid line.

ties of the spectra are listed in Table 3, which presents the relative intensities of the five features and lists the emission lines of individual ions. The $650 \mathrm{eV}$ feature is produced by a mixture of lines of $\mathrm{O}^{+7}$ and $\mathrm{O}^{+6}$. The $3{ }^{1} P_{1} \rightarrow 1{ }^{1} S_{0}$ and $4^{1} P_{1} \rightarrow 1{ }^{1} S_{0}$ transitions of $\mathrm{O}^{+6}$ at 664 and $697 \mathrm{eV}$, respectively, lie higher in energy than the Ly $\alpha$ line of the more highly charged $\mathrm{O}^{+7}$ ion at $654 \mathrm{eV}$.

The relative intensities of emission lines of individual ions depend on the ion abundances in the solar wind and on the total cross sections for charge transfer collisions with the cometary gas. In our calculations, we have adopted the total charge transfer cross sections measured for individual ions colliding with $\mathrm{H}_{2} \mathrm{O}$ molecules by Greenwood et al. (2000, 2001). Figure 1 is a comparison of the predicted spectrum for abundance ratios of the solar wind ions $\left[\mathrm{O}^{+8}\right] /\left[\mathrm{O}^{+7}\right]=0.34$ and $\left[\mathrm{Ne}^{+9}\right] /\left[\mathrm{O}^{+7}\right]=0.02$ degraded to an FWHM resolution of $45 \mathrm{eV}$ and the best-fit curve derived from measurements of comet McNaught-Hartley (Krasnopolsky et al. 2002). The sensitivity of the fit to the ratio is illustrated in Figure 2, where spectra corresponding to different values of the ratio $\left[\mathrm{O}^{+8}\right] /\left[\mathrm{O}^{+7}\right]$ are presented. It seems safe to conclude that $\left[\mathrm{O}^{+8}\right] /\left[\mathrm{O}^{+7}\right]=0.34 \pm 0.07$. The charge composition of heavy solar wind ions undergoes strong spatial and temporal variations (von Steiger et al. 1992, 2000). The ratio we have derived agrees with the average of 0.35 suggested by Schwadron \& Cravens (2000) for the slow solar wind. The com-

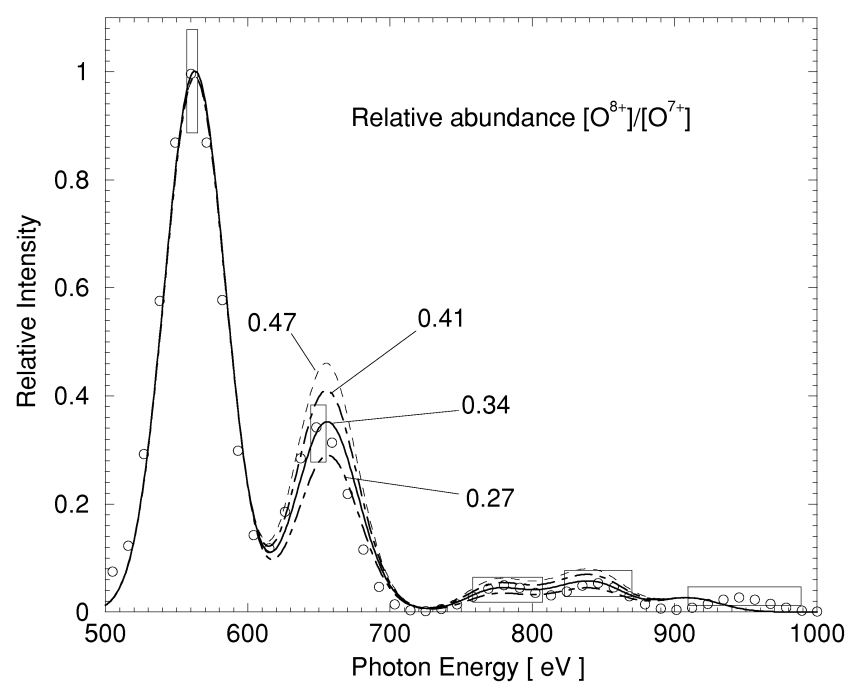

FIG. 2.-Cometary emission spectrum calculated for different abundances of solar wind ions $\left[\mathrm{O}^{+7}\right],\left[\mathrm{O}^{+8}\right]$, and $\left[\mathrm{Ne}^{+9}\right]$. The data from the best-fit curve of the X-ray spectrum of comet McNaught-Hartley are shown by circles. Error bars are indicated by the boxes. The solid line is the theoretical spectrum calculated for the ion abundances $\left[\mathrm{O}^{+7}\right]:\left[\mathrm{O}^{+8}\right]:\left[\mathrm{Ne}^{+9}\right]=1: 0.34: 0.02$. The dashed line represents the theoretical spectrum induced by the solar wind with a relative abundance of $\left[\mathrm{O}^{+8}\right]$ ions of 0.47 , and the dot-dashed lines are the spectra for abundances of 0.27 and 0.41 . These two curves indicate the limits consistent with the error bars of the measurements.

etary data show a deep minimum in the region of $500 \mathrm{eV}$, where the $\mathrm{Ly} \alpha$ line of $\mathrm{N}^{+6}$ is located. The lack of a feature is marginally consistent with the average value of 0.03 for the population ratio of $\mathrm{N}^{+7}$ to $\mathrm{O}^{+7}$ ions in the slow solar wind given by Schwadron \& Cravens (2000).

Charge transfer collisions of the solar wind ions with neutral atoms in the heliospheric gas and in the geocorona may contribute to measurements of the diffuse soft X-ray background (Cravens 2000; Cravens, Robertson, \& Snowden 2001). Highresolution measurements of the X-ray background by McCammon et al. (2002) yield an intensity ratio of $0.33 \pm 0.13$ for emission features in the region of $561-574 \mathrm{eV}$ and $654 \mathrm{eV}$, attributable to lines of $\mathrm{O}^{+6}$ and $\mathrm{O}^{+7}$, which happens to agree with the ratio expected from solar wind ions undergoing charge transfer in a mixture of hydrogen and helium atoms. Individual $\mathrm{X}$-ray lines emitted by the triplet $2{ }^{3} S, 2{ }^{3} \mathrm{P}$ and singlet $2{ }^{1} \mathrm{P}$ excited states of helium-like oxygen and carbon ions may provide an opportunity to distinguish between different mechanisms of X-ray excitation. The ratio of intensities of the triplet to singlet transitions is predicted to be in excess of 3 for the charge transfer mechanism but to be comparable to unity or less in a hot plasma (Smith et al. 2001). The strongest spectral feature of the cometary X-ray emission at $560 \mathrm{eV}$ detected recently with the Chandra X-ray telescope (Lisse et al. 2001; Krasnopolsky et al. 2002) corresponds to the $2{ }^{3} S \rightarrow 1{ }^{1} S$ emission line of $\mathrm{O}^{+6}$ ions at $561 \mathrm{eV}$ (Kharchenko \& Dalgarno 2000,
TABLE 1

Relative InTENSities of $\mathrm{O}^{+6}$ EMission Lines

\begin{tabular}{lccc}
\hline \hline Line Index & Transition & $\begin{array}{c}\text { Energy } \\
(\mathrm{eV})\end{array}$ & Relative Intensity \\
\hline $1 \ldots \ldots \ldots \ldots$ & $2{ }^{3} S \rightarrow 1{ }^{1} S$ & 561 & 100 \\
$2 \ldots \ldots \ldots \ldots$ & $2{ }^{3} P \rightarrow 1{ }^{1} S$ & 568 & 16.0 \\
$3 \ldots \ldots \ldots$. & $2{ }^{1} P \rightarrow 1{ }^{1} S$ & 574 & 9.30 \\
$4 \ldots \ldots \ldots$. & $3{ }^{3} P \rightarrow 1{ }^{1} S$ & 664 & 0.18 \\
$5 \ldots \ldots \ldots \ldots$ & $3{ }^{1} P \rightarrow 1{ }^{1} S$ & 666 & 9.70 \\
$6 \ldots \ldots \ldots$. & $4{ }^{1} P \rightarrow 1{ }^{1} S$ & 697 & 0.53 \\
\hline
\end{tabular}

TABLE 2

Relative InTEnsities of $\mathrm{O}^{+7}$ EMission Lines

\begin{tabular}{lccc}
\hline \hline Line Index & Transition & $\begin{array}{c}\text { Energy } \\
(\mathrm{eV})\end{array}$ & Relative Intensity \\
\hline $7 \ldots \ldots \ldots$. & $2 p \rightarrow 1 s$ & 654 & 100 \\
$8 \ldots \ldots \ldots$. & $3 p \rightarrow 1 s$ & 774 & 14.6 \\
$9 \ldots \ldots \ldots$. & $4 p \rightarrow 1 s$ & 816 & 8.8 \\
$10 \ldots \ldots \ldots$ & $5 p \rightarrow 1 s$ & 836 & 0.73 \\
$11 \ldots \ldots \ldots$ & $6 p \rightarrow 1 s$ & 847 & 15.7 \\
\hline
\end{tabular}


TABLE 3

Relative Intensities of the X-Ray Emission Features

\begin{tabular}{crlll}
\hline \hline $\begin{array}{c}\text { Energy } \\
(\mathrm{eV})\end{array}$ & Observations & \multicolumn{1}{c}{ Theory } & \multicolumn{1}{c}{ Emission Lines } & \multicolumn{1}{c}{$\begin{array}{c}\text { Emission Lines } \\
(\mathrm{eV})\end{array}$} \\
\hline $560 \pm 3 \ldots \ldots$ & $1 \pm 0.09$ & 1 & $\mathrm{O}^{+6}\left(2{ }^{3} S,{ }^{3} P,{ }^{1} P \rightarrow 1{ }^{1} S\right)$ & 561,568 , and 574 \\
$650 \pm 6 \ldots \ldots$. & $0.34 \pm 0.05$ & 0.35 & $\mathrm{O}^{+6}\left(3{ }^{1,3} P, 4{ }^{1} P \rightarrow 1{ }^{1} S\right)$ and $\mathrm{O}^{+7}(2 p \rightarrow 1 s)$ & $664,666,697$, and 654 \\
$780 \pm 23 \ldots \ldots$ & $0.050 \pm 0.020$ & 0.051 & $\mathrm{O}^{+7}(3 p, 4 p \rightarrow 1 s)^{\mathrm{a}}$ & 774 and 816 \\
$845 \pm 19 \ldots \ldots$ & $0.054 \pm 0.020$ & 0.059 & $\mathrm{O}^{+7}(4 p, 5 p, 6 p \rightarrow 1 s)^{\mathrm{a}}$ & 816,836 , and 847 \\
$945 \pm 34 \ldots \ldots$ & $0.027 \pm 0.014$ & 0.028 & $\mathrm{Ne}^{+8}\left(2{ }^{3} S,{ }^{3} P,{ }^{1} P \rightarrow 1{ }^{1} S\right)$ & 905,915 , and 922 \\
\hline
\end{tabular}

${ }^{a}$ The intensity of the emission line $\mathrm{O}^{+7}(4 p \rightarrow 1 s)$ is included in the closest features at 780 and $845 \mathrm{eV}$ assuming a Gaussian distribution for the detector resolution function.

2001). This is direct evidence for the charge transfer mechanism as the source of cometary X-rays.

$\mathrm{X}$-ray spectra arising from electron capture by highly charged ions are insensitive to the target gases, particularly when the gases have similar ionization potentials (Greenwood et al. 2000, 2001), and we do not expect that any changes in our conclusions would result from the replacement of water by its dissociation products.

Our detailed analysis confirms that charge transfer is the dominant mechanism for the production of X-rays in comets and demonstrates that the spectrum can be interpreted to provide a measure of the solar wind heavy ion composition.

\section{REFERENCES}

Beiersdorfer, P., Lisse, C. M., Olson, R. E., Brown, G. V., \& Chen, H. 2001, ApJ, 549, L147

Cravens, T. E. 1997, Geophys. Res. Lett., 24, 105

- 2000, ApJ, 532, L153 2002, Science, 296, 1042

Cravens, T. E., Robertson, I. P., \& Snowden, S. L. 2001, J. Geophys. Res., $106,24,883$

Dennerl, K., Englhauser, J., \& Trümper, J. 1997, Science, 277, 1625

Drake, G. W. F. 1971, Phys. Rev. A, 3, 908

Drake, G. W. F., \& Dalgarno, A. 1969, ApJ, 158, 1199

Greenwood, J. B., Williams, I. D., Smith, S. J., \& Chutjian, A. 2000, ApJ, 533, L175

2001, Phys. Rev. A, 63, 062707

Johnson, W. R., Savukov, I. M., Safronova, U. I., \& Dalgarno, A. 2002, ApJS, 141,543

Kharchenko, V., \& Dalgarno, A. 2000, J. Geophys. Res., 105, 18,351

- 2001, ApJ, 554, L99

Krasnopolsky, V. A., Christian, D. J., Kharchenko, V., Dalgarno, A., Wolk, S. J., Lisse, C. M., \& Stern, S. A. 2002, Icarus, 160, 437

Krasnopolsky, V. A., \& Mumma, M. J. 2001, ApJ, 549, 629
Krasnopolsky, V. A., Mumma, M. J., \& Abbott, M. J. 2000, Icarus, 146, 152 Krasnopolsky, V. A., Mumma, M. J., Abbott, M., Flynn, B. C., Meech, K. J., Yeomans, D. K., Feldman, P. D., \& Cosmovici, C. V. 1997, Science, 277, 1488

Lisse, C. M., Christian, D. J., Dennerl, K., Meech, K. J., Petre, R., Weaver, H. A., \& Wolk, S. J. 2001, Science, 292, 1343

Lisse, C. M., et al. 1996, Science, 274, 205

_. 1999a, Earth Moon Planets, 77, 283 . 1999b, Icarus, 141, 316

McCammon, D., et al. 2002, ApJ, 576, 188

Mumma, M. J., Krasnopolsky, V. A., \& Abbott, M. J. 1997, ApJ, 491, L125 Owens, A., et al. 1998, ApJ, 493, L47

Rigazio, M., Kharchenko, V., \& Dalgarno, A. 2002, Phys. Rev. A, 66, 64701 Schwadron, N. A., \& Cravens, T. E. 2000, ApJ, 544, 558

Smith, R. K., Brickhouse, N. S., Liedahl, D. A., \& Raymond, J. C. 2001, ApJ, 556, L91

von Steiger, R., Christon, S. P., Gloeckler, G., \& Ipavich, F. M. 1992, ApJ, 389, 791

von Steiger, R., et al. 2000, J. Geophys. Res., 105, 27,217 